\begin{tabular}{|c|l|}
\hline Title & Heterogeneous oceanic mass distribution in GRA CE observations and its leakage effect \\
\hline Author(s) & Heki, Kosuke; Y i, Shuang \\
\hline Citation & $\begin{array}{l}\text { Geophysical Journal International, 221(1), 603-616 } \\
\text { https://doi.org/10.1093/gij//ggaa022 }\end{array}$ \\
\hline Issue Date & 2020-04 \\
\hline Doc URL & http://hdl.handle.net/2115/80484 \\
\hline Rights & $\begin{array}{l}\text { This article has been accepted for publication in Geophysical Journal International @:2020 The A uthors Published by } \\
\text { Oxford University Press on behalf of the Royal A stronomical Society. All rights reserved. }\end{array}$ \\
\hline Type & article \\
\hline File Information & \begin{tabular}{l} 
Geophys. J. Int. 221_603-616.pdf \\
\hline
\end{tabular} \\
\hline
\end{tabular}

Instructions for use 


\title{
Heterogeneous oceanic mass distribution in GRACE observations and its leakage effect
}

\author{
Shuang $\mathrm{Yi}^{1,2}$ and Kosuke Heki ${ }^{2}$ \\ ${ }^{1}$ Institute of Geodesy, University of Stuttgart, Stuttgart 70174, Germany. E-mail: shuangyi.geo@gmail.com \\ ${ }^{2}$ Department of Earth and Planetary Sciences, Hokkaido University, Sapporo 0600808, Japan
}

Accepted 2020 January 9. Received 2020 January 8; in original form 2019 July 17

\begin{abstract}
SUMMAR Y
Signal leakage between the land and ocean is a challenge in using Gravity Recovery and Climate Experiment (GRACE) observation data to study global mass redistributions. Although the leakage occurs in both directions, more attention has been paid to the land-to-ocean leakage and less to the ocean-to-land leakage. Here, we show that the ocean-to-land leakage is nonuniform and non-negligible and propose a new forward modelling method to fully consider bi-directional leakages with the help of the global Ocean ReAnalysis System ORAS5. This observation-driven model could significantly reduce the variations in ocean grids and thus decrease the ocean-to-land leakage. The results with different treatment of the ocean signal leakage are compared. We find that failing to consider the ocean-to-land leakage will cause an underestimation of $\sim 20$ per cent in the seasonal variation and will introduce a bias of several giga-tons in the secular trend. Although the uniform and non-uniform model have similar results in the global average of seasonal mass variations, the non-uniform ocean model is necessary in most places, especially near the Arctic Ocean, the Sea of Japan and the Gulf of Carpentaria. Despite these achievements, we also point out that there is still much room for improvement in ocean mass models, particularly in long-term trends. Our results indicate the importance of the ocean-to-land leakage correction in the mass estimation in coastal land areas using the GRACE data.
\end{abstract}

Key words: Global change from geodesy; Satellite gravity; Sea level change; Time variable gravity.

\section{INTRODUCTION}

Gravity Recovery and Climate Experiment (GRACE) products have been published as the Stokes' coefficients (spherical harmonic coefficients, SHCs, Bettadpur 2012). Gravity fields expressed with SHCs are spatially smooth, and a finite number of SHCs cannot accurately simulate the actual mass distribution that often has sharp boundaries. Hence, the gravity models reconstructed from SHCs usually present skewed patterns extending beyond the actual signal area with diminished intensity. This is known as the leakage (Wahr et al. 1998; Wiese et al. 2016). The leakage occurring in both directions is composed of leakage-in and leakage-out effects. Since there may be two unknowns in each observation, it is troublesome to solely depend on GRACE observations to scrutinize them. There are generally two ways to separate and correct these two leakage effects. One is to put different smooth constraints into different signal sources (from a prior information) so that no other observations are needed. This strategy has been widely adopted in GRACE Mascon products (e.g. Luthcke et al. 2013; Watkins et al. 2015). The other is to incorporate other independent observations to remove the leakage-in effect (e.g. Sørensen et al. 2017; Huang et al. 2019) and use a technique to restore the leakage-out afterwards [such as scaling factors (Velicogna \& Wahr 2006), point-mass method (Baur et al. 2009) and forward modelling method (Chen et al. 2013)]. The leakage problem is diverse in different locations and different signal sources. Here, we will investigate the less-discussed ocean leakage and adopt an ocean mass model to correct it.

It is well recognized that coastal land signals derived from GRACE SHCs products may leak into nearby oceans (Chen et al. 2013), so we need to add these leaked signals back to the land mass to avoid its underestimation (Chen et al. 2013). Fig. 1 illustrates this problem with a profile across the equator of a simplified landocean model (Yi et al. 2017). Considering global conservation of water mass, a decrease of water mass storage on land will result in an increase of the ocean mass by the same amount. Since the land to ocean areal ratio is approximately $3: 7$, the ratio of their average mass anomalies will be $7: 3$, which means that the anomalies on land are more than twofold (Fig. 1a). The realistic distribution of mass anomalies is highly heterogeneous (Fig. 1b). Usually, mass anomalies are concentrated near the coast (less than hundreds of kilometres), where more precipitation and ice melting take place (Gardner et al. 2013). Gravity signals of land/ocean mass 
(a) Schematic diagram of leakage effects

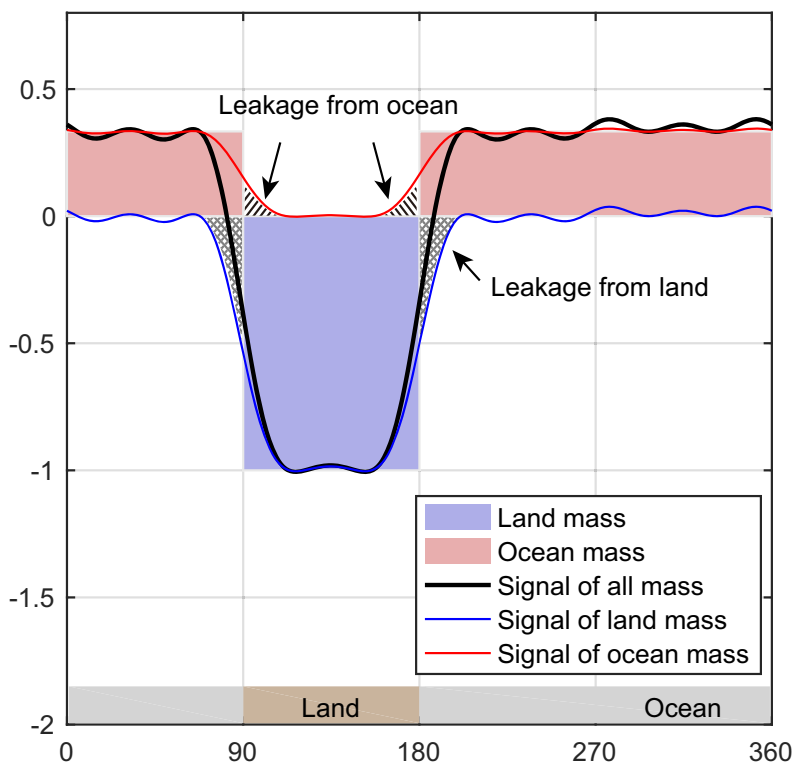

(b) inhomogeneous mass distribution

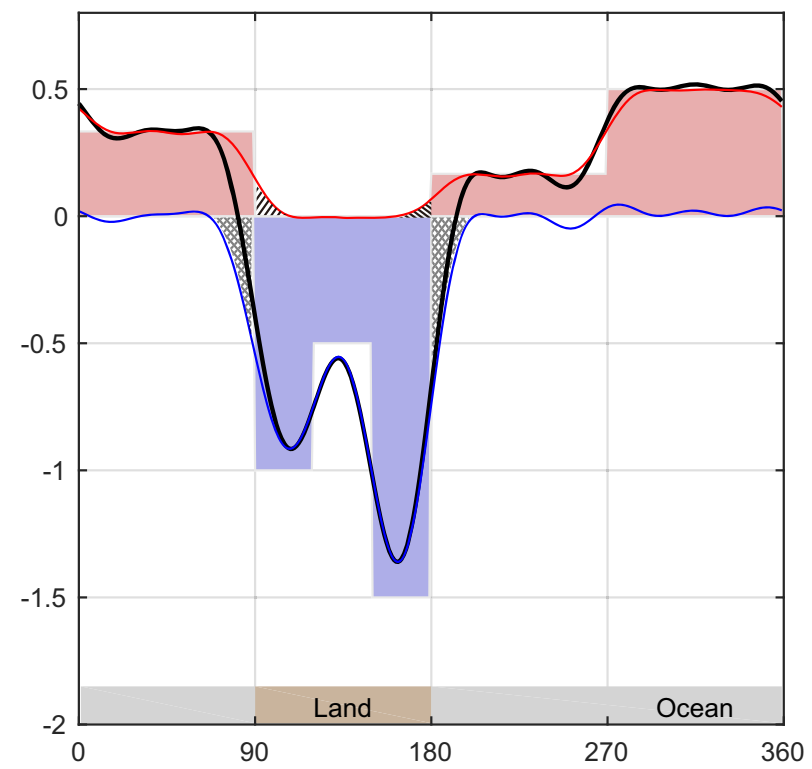

Figure 1. Schematic diagrams along the equator showing bi-directional leakage effects of a simple mass distribution (a) and a more complex distribution (b). Here, we assume a simple earth composed of only one land and ocean.

anomalies will leak into ocean/land regions and cause an underestimate of the mass changes on land/ocean through two mechanisms. On the one hand, the gravity signal on the land/ocean is reduced because a part of the coastal mass changes leaks out. On the other hand, the signals leaking in from the other regions always have the opposite sign. Therefore, both leakage effects should be corrected to avoid the underestimation. However, only the leakage from the land (land-to-ocean leakage) is well recognized until now, while the leakage from the ocean (ocean-to-land leakage) was either neglected or averaged from nearby ocean grids (Guo et al. 2010; Wiese et al. 2016).

The forward modelling method was proposed to recover mass changes at regional (e.g. Wouters et al. ; King et al. 2012) and global (e.g. Chen et al. 2013; Yi et al. 2017) scales. The main change in the global application is to place a uniform water layer with the inverse sign in the ocean area to guarantee that the sum of global mass changes is zero. This water layer oversimplifies ocean mass distributions, and therefore does not consider the ocean-toland leakage properly. We will show that the residual ocean signals in GSM are far from uniform, and that over-/underestimation of ocean mass will cause significant deviations in mass estimates of nearby land areas.

Non-uniform distribution of ocean mass is caused by two factorsocean dynamics and gravitational attraction from land and atmosphere, called sea level fingerprints (Mitrovica et al. 2009; Hsu \& Velicogna 2017). The later can be precisely modelled by sea level equations (Mitrovica et al. 2009), and one previous study showed that it is detectable in the latest observations (Hsu \& Velicogna 2017). However, the ocean dynamic changes vary at different spatial and temporal scales, making it difficult to simulate the distribution of ocean mass. Seasonal ocean water mass variations of up to $4000 \mathrm{Gt}$ per year may be more concentrated in certain coastal areas, especially in semi-enclosed seas. The long-term ocean water mass increase, mainly resulting from groundwater depletion and ice melting (Church et al. 2013), is observed to be over $2 \mathrm{~mm} \mathrm{yr}^{-1}$ (e.g. Chambers et al. 2017; Dieng et al. 2017) during the period of
GRACE operation. A preliminary non-uniform forward modelling method based on sea level fingerprints was also designed to consider the non-uniform ocean mass distribution (Jeon et al. 2018). However, because not all the ocean dynamic processes are well simulated and eliminated in GRACE products, the residual ocean dynamics effects are non-negligible. Therefore, we consider it necessary to introduce another ocean mass product to improve the correction of ocean-to-land leakage.

In this study, we will first demonstrate the merits and demerits of a new ocean mass product by comparing it with the GRACE build-in one. We then will introduce a non-uniform forward modelling method based on the ocean mass product. The result by the new method will be compared to these by noncorrection and uniform correction of the ocean signal leakage at seasonal and long-term timescales to quantify its significance. Finally, the reliability and uncertainty of this new method will be discussed.

\section{DATA}

\subsection{GRACE products}

The GRACE observation of gravity field change resulting from miscellaneous mass transports in the earth is separated into several products for different application purposes. Atmospheric and non-tidal oceanic mass changes are modelled based on numerical simulations performed by the European Centre for Medium-Range Weather Forecasts (ECMWF) and the Max-Planck-Institute for Meteorology Ocean Model (MPIOM), resulting in the Atmosphere and Ocean De-Aliasing Level-1B (AOD1B) product, which consists sub-products of GAA, GAB, GAC and GAD (Dobslaw et al. 2017). After the AOD1B products are corrected from GRACE observations, we get the GSM product (GSM and GAx are all GRACE product identifiers), which reflects hydrospheric, cryospheric and tectonic mass transports in the earth and uncorrected atmosphere and oceans dynamics due to the imperfect models. 
For ocean mass applications, we need to add back the GAD or $\mathrm{GAB}$ product to GSM. Compared with GAD, GAB corrects the Inverted Barometer (IB) effect of the atmospheric surface pressure and excludes the upper-air atmospheric mass, and is suitable for mass-induced ocean variations (Dobslaw et al. 2017). Their physical relationship is:

$\Delta \mathrm{OBP}=\Delta M_{\text {ocean }}+\Delta \mathrm{M}_{\mathrm{atm}}=\Delta \mathrm{GSM}^{\prime}+\Delta \mathrm{GAD}$,

$\Delta M_{\text {ocean }}=\Delta \mathrm{GSM}^{\prime}+\Delta \mathrm{GAB}$,

where OBP is ocean bottom pressure, $M_{\text {ocean }}$ is ocean water mass, $M_{\text {atm }}$ is the total mass of atmosphere column integrated from the top of the atmosphere to the ocean surface (i.e. atmosphere pressure on the ocean surface). Note the pressure equals the gravitational force of the mass applied on a unit area and the unit area is omitted here. The prime sign means only the ocean part is used. $\Delta$ means only the anomaly relative to the long-term average is investigated here.

We adopt the GRACE L2 RL06 data set from January 2005 to December 2016 processed by the Center for Space Research at the University of Texas (CSR-UT). The $\mathrm{C}_{20}$ term is replaced by the more accurate one by satellite laser ranging (Cheng et al. 2011) and the geocentre ones are added by the approach proposed by Swenson et al. (2008). Note that the GAB product is not available from CSR (while it is available from competitive products of the GFZ German Research Centre and Jet Propulsion Laboratory at California Institute of Technology, but different GAB products are not interchangeable). However, it is easy to derive the GAB product by the IB correction (Uebbing et al. 2019) from their GAD product, which is always released with the GSM product.

Here, we investigate seasonal and long-term changes separately. For seasonal changes, we removed the trend and acceleration of each coefficient and averaged these in the same month, so we finally got 12 sets of SHCs. For long-term changes, we calculated the trend of each coefficient, which was further corrected by a Glacial Isostatic Adjustment (GIA) model (A et al. 2013). The same averaging and fitting processing will be applied to the ocean product below. The results shown in this study are in terms of equivalent water height (EWH). The forward and inverse transformation between gridded observations of EWH and SHCs are expressed as:

$$
\begin{aligned}
\Delta \sigma(\theta, \phi)= & \frac{a \rho_{e}}{3 \rho_{w}} \sum_{n=0}^{N}\left(\frac{2 n+1}{1+k_{n}}\right) \sum_{m=0}^{n}\left\{\left[\Delta C_{n}^{m} \cos (m \phi)\right.\right. \\
& \left.+\Delta S_{n}^{m} \sin (m \phi)\right] P_{n}^{m}(\cos (\theta)\}, \\
\left\{\begin{array}{c}
\Delta C_{n}^{m} \\
\Delta S_{n}^{m}
\end{array}\right\}= & \frac{13}{4 \pi a \rho_{e} 2 n+1} \iint_{S} \Delta \sigma(\xi, \eta)\left\{\begin{array}{l}
\cos (m \xi) \\
\sin (m \xi)
\end{array}\right\} \\
& \times P_{n}^{m}(\cos \eta) \sin \eta \mathrm{d} \xi \mathrm{d} \eta,
\end{aligned}
$$

where $\left(C_{n}^{m}, S_{n}^{m}\right)$ are set of SHCs with a maximum degree of $N$, $P_{n}^{m}$ is the associated Legendre function, $(\theta, \phi)$ or $(\xi, \eta)$ are colatitude/longitude of observations, $\sigma$ are gridded observations of EWH, $a$ and $\rho_{e}$ are, respectively, the mean radius and the mean density of the Earth, $\rho_{w}$ is the density of water, $k_{n}$ is the loading Love number, $\Delta$ means only anomalies are concerned and $S$ represents integration over the sphere.

\subsection{Ocean product ORAS5}

ORAS5 is the product of the ECMWF OCEANS reanalysis-analysis system, a global eddy-permitting ocean-sea ice ensemble system of five members (Zuo et al. 2019). Its data assimilation system includes temperature and salinity profiles, altimetry-derived sea level anomalies, sea-ice concentration and sea surface temperature. This is different from AOD1B products that are driven only by atmospheric forcing. It is an up-to-date systematic production with improvements in the ensemble generation strategy and data assimilation. For the purpose of this study, the main advantage of this product is that it incorporates both sea level anomaly and key ocean state variables, which can be used to derive ocean mass change without additional auxiliary data. Its spatial resolution is down to $0.25^{\circ}$ by $0.25^{\circ}$ (here we only use the version of $1^{\circ}$ by $1^{\circ}$ ) in global oceans and contains 75 layers of ocean water temperature and salinity down to $5902.1 \mathrm{~m}$ deep.

We derived ocean steric change $\left(H_{\text {steric }}\right.$, which represents densityinduced sea level changes due to the variations in seawater temperature and salinity) from the 75 layers of temperature and salinity (Fofonoff \& Millard Jr 1983). The observed sea level changes consist of ocean mass changes and steric changes, so we can derive mass change $\left(M_{\text {ocean }}^{\prime}\right)$ from the difference between the ocean surface height $\left(H_{\text {height }}\right)$ and the steric change:

$\Delta M_{\text {ocean }}^{\prime}=\Delta H_{\text {height }}-\Delta H_{\text {steric }}$.

\section{UNEVEN OCEAN MASS VARIATIONS}

The observation of total mass change is obtained by the sum of GAB and GSM products of GRACE, and the rms of its seasonal variation is shown in Fig. 2(a). The variation is much reduced in the GSM production (Fig. 2b), indicating that GAB can successfully remove most of the ocean dynamics. However, significant residual signals in GSM can still be identified in the Arctic Ocean, the Gulf of Carpentaria, the Sea of Japan and some other coastal areas. A previous study (Mu et al. 2019) also highlighted this spatial variation in the global coastal ocean mass distribution. Besides, GAB always has a zero net mass change throughout the ocean region, so an annual mass exchange of $\sim 4000$ Gt between land and ocean is retained in GSM. Therefore, significant regional and overall ocean mass variations exist in GSM and their leakage needs to be considered in the estimation of land mass. To this end, we adopt the ocean mass derived from the ORAS5 model. It is found that the spatial variation of the modelled mass roughly agrees with that of the GRACE observations (see Figs $2 \mathrm{a}$ and $\mathrm{c}$ ), which is a promising sign for our following method.

Compared with the GAB-corrected result (i.e. GSM), the variation in ORAS5-corrected ocean mass is indeed significantly reduced (Fig. 2d). However, significant variations still can be found, especially in the oceans near Canada-Greenland and Novaya Zemlya. Such substantial variations do not exist before the correction, so they must be caused by flaws in the ocean mass model.

The performance of these two ocean mass models at six coastal spots (the locations of which are shown in Fig. 2) is specially examined in Fig. 3. Their variations range from \pm 2 to $\pm 20 \mathrm{~cm}$, demonstrating that the ocean mass redistribution is highly heterogeneous. The GAB product works well in some places, such as the Red Sea (spot-d), but may perform insufficiently in some places like the Gulf of Carpentaria (spot-a) and the East Siberian Sea (spot-e). In addition, the GAB product could also behave unexpectedly to exaggerate the initial variations in some places like the Sea of Japan (spot-b) and the Gulf of Mexico (spot-c). The ORAS5 model is capable of alleviating most of these problems with an rms reduction of $\sim 50$ per cent, despite that it may also suffer from dubious performance (spot-f). 
(a) RMS of Ocean mass by GRACE observation

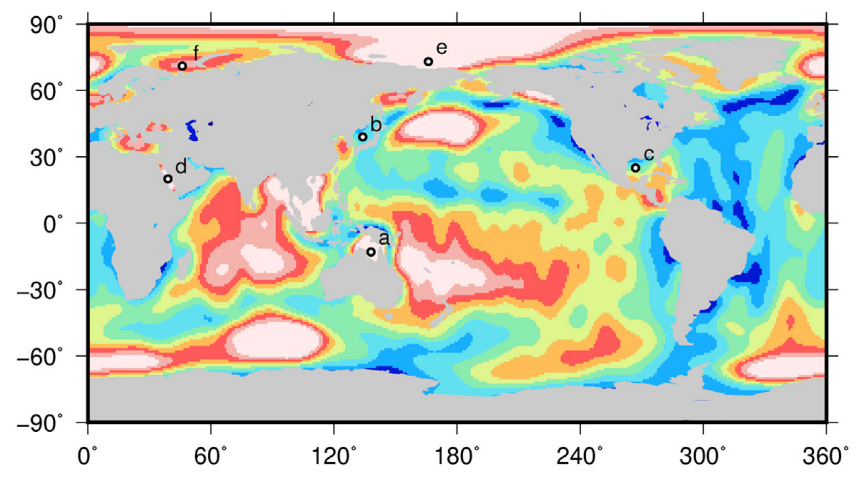

(c) RMS of Ocean mass by ORAS5 model

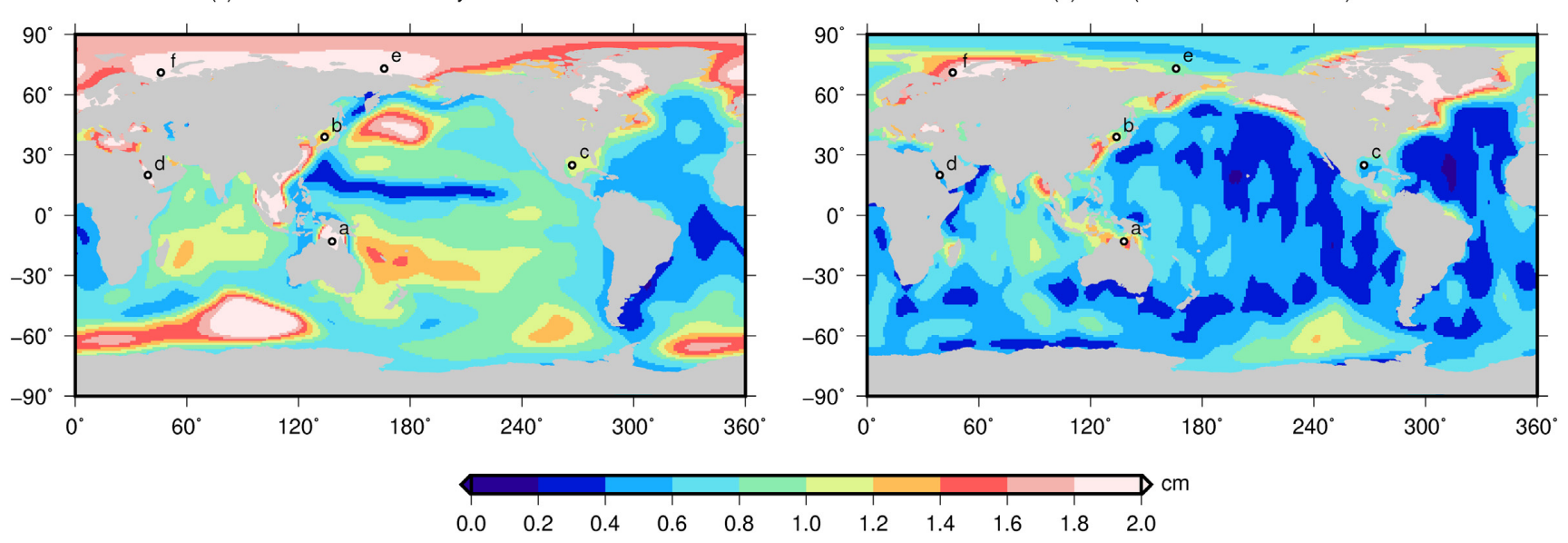

Figure 2. Seasonal ocean mass variabilities ( $\mathrm{rms}$ ) in various datasets in terms of EWH. The rms of ocean mass without atmospheric mass contribution observed by GRACE is shown in (a). Two different model-based correction results, GAB-corrected (i.e. the GSM product) and ORAS5-corrected, are given in (b) and (d), respectively. The rms result of the ORAS5 model is given in (c). It is shown that the ORAS5 product could better reduce the rms of ocean mass in most ocean areas than the GAB product, but may perform poorly especially in arctic coastal regions.

\section{METHOD OF OCEAN-TO-LAND LEAKAGE CORRECTION}

The basic idea of the ocean-to-land leakage correction is to use ocean mass models $\left(M_{\mathrm{ocean}}^{\text {model }}\right)$ to correct the observations $\left(M_{\mathrm{ocean}}^{\mathrm{obs}}\right)$, and the residuals $\left(\delta_{\text {ocean }}\right)$ include the leakage from land $\left(L_{\text {land }}\right)$ and model imperfections $(e)$ :

$\delta_{\text {ocean }}=M_{\text {ocean }}^{\text {obs }}-M_{\text {ocean }}^{\text {model }}=L_{\text {land }}+e$.

The next step is to estimate $e$ without the influence of $L_{\text {land }}$. The land-to-ocean leakage is located only in coastal areas, so we can discard these coastal grids and fill these voids by interpolation from adjacent ocean areas. This step assumes that there is no local variation in the residual ocean signals $\left(\delta_{\text {ocean }}\right)$ in the coastal areas, so the interpolation from further grids can restore the coastal values. The GSM product apparently holds many local variations, as shown in Figs 2 and 3, so the interpolation method will not work well. We need to further suppress mass variations in the GSM product, and another ocean mass product from the ORAS5 model could be helpful.

As shown above, the ORAS5 product may outperform the GAB product in some regions but underperform in others, so we implement a joint ocean mass correction by putting a spatial mask function to choose the product with the better performance. The

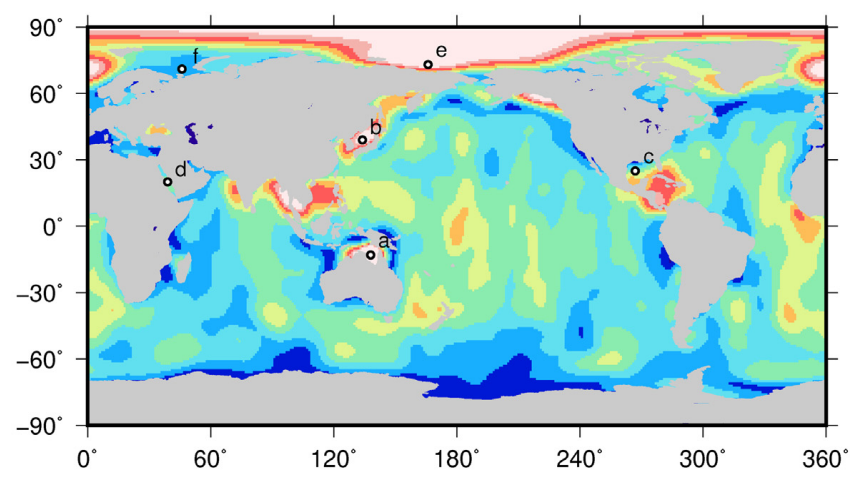

(d) RMS( observation - model ) criterion is straightforward: the ocean mass product (either ORAS5 or $\mathrm{GAB}$ ) that can reduce the RMS of mass variation in one grid to a greater extent will be used for that grid. The ORAS5-corrected and GAB-corrected results are compared in Figs 4(a) and a ratio $<1$ indicates a better performance of the ORAS5 model. Although ORAS5 always outperform GAB in the open oceans, these two products show comparable results in coastal ocean areas, where the leakage mainly happens. We extract mass anomalies in oceanic grids within $500 \mathrm{~km}$ from the coast after ocean mass correction and compare their statistical distributions in Fig. 5(a). Generally, these two products exhibit similar performance in coastal regions. Specifically, the ORAS5 product is a better choice for 42 per cent of coastal grids while the GAB product is better for the others. The joint correction could significantly reduce the variance in coastal regions compared with a single correction, as shown in Fig. 5(b). The joint correction with the mask function can be written as:

$$
\begin{aligned}
\delta_{\text {ocean }} & =\mathrm{GSM}^{\prime}+\mathrm{GAB}-\operatorname{mask}(\mathrm{GAB}, \text { ORAS5 }) \\
& =\mathrm{GSM}^{\prime}-\operatorname{mask}(0, \text { ORAS5 }-\mathrm{GAB}) .
\end{aligned}
$$

The land leakage $L_{\text {land }}$ could be removed in two steps. First, the SHCs are converted into a global gridded EWH (eq. 3, Wahr et al. 1998) without any smoothing, so the leakage is minimal. We then 

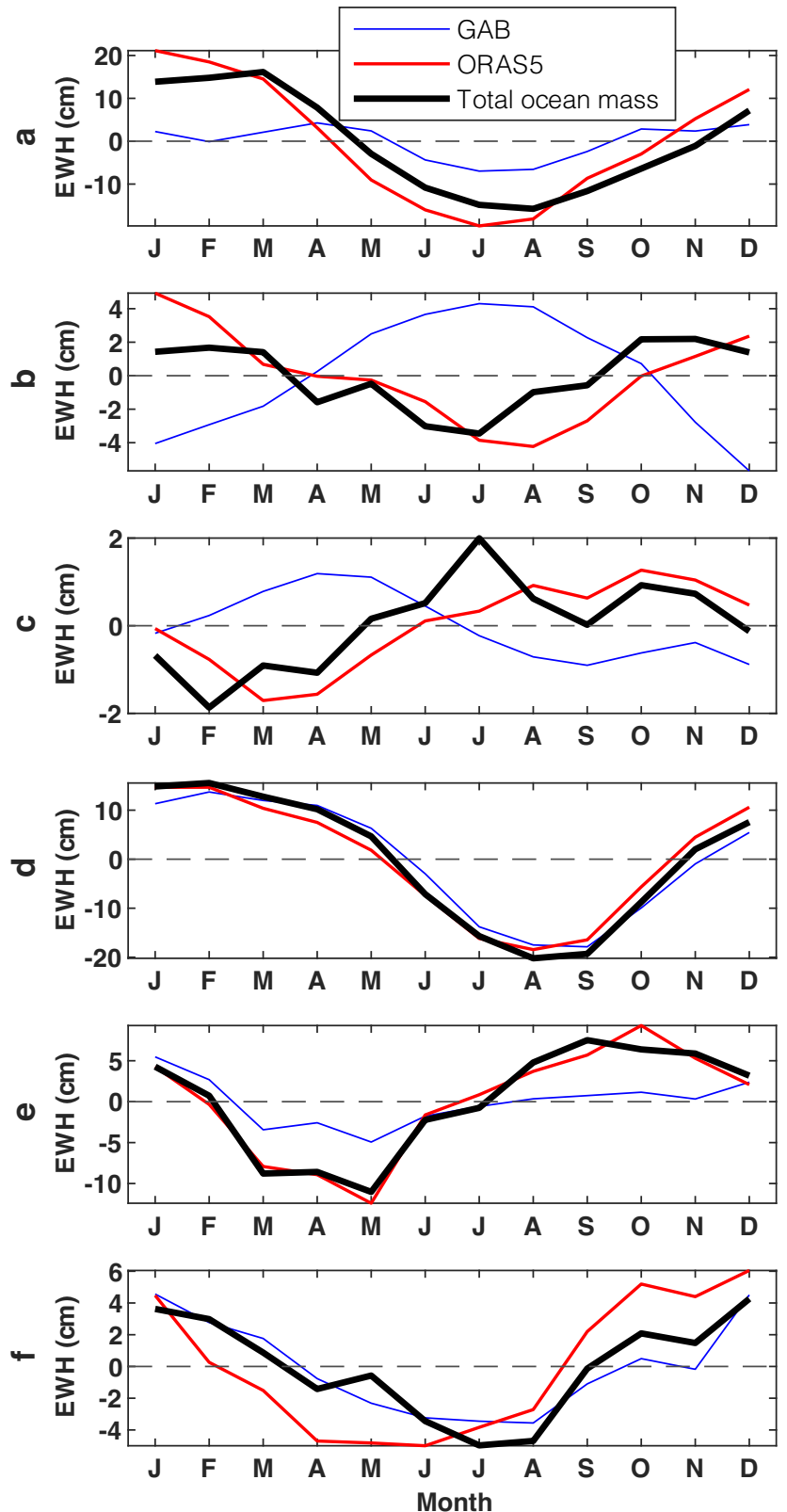
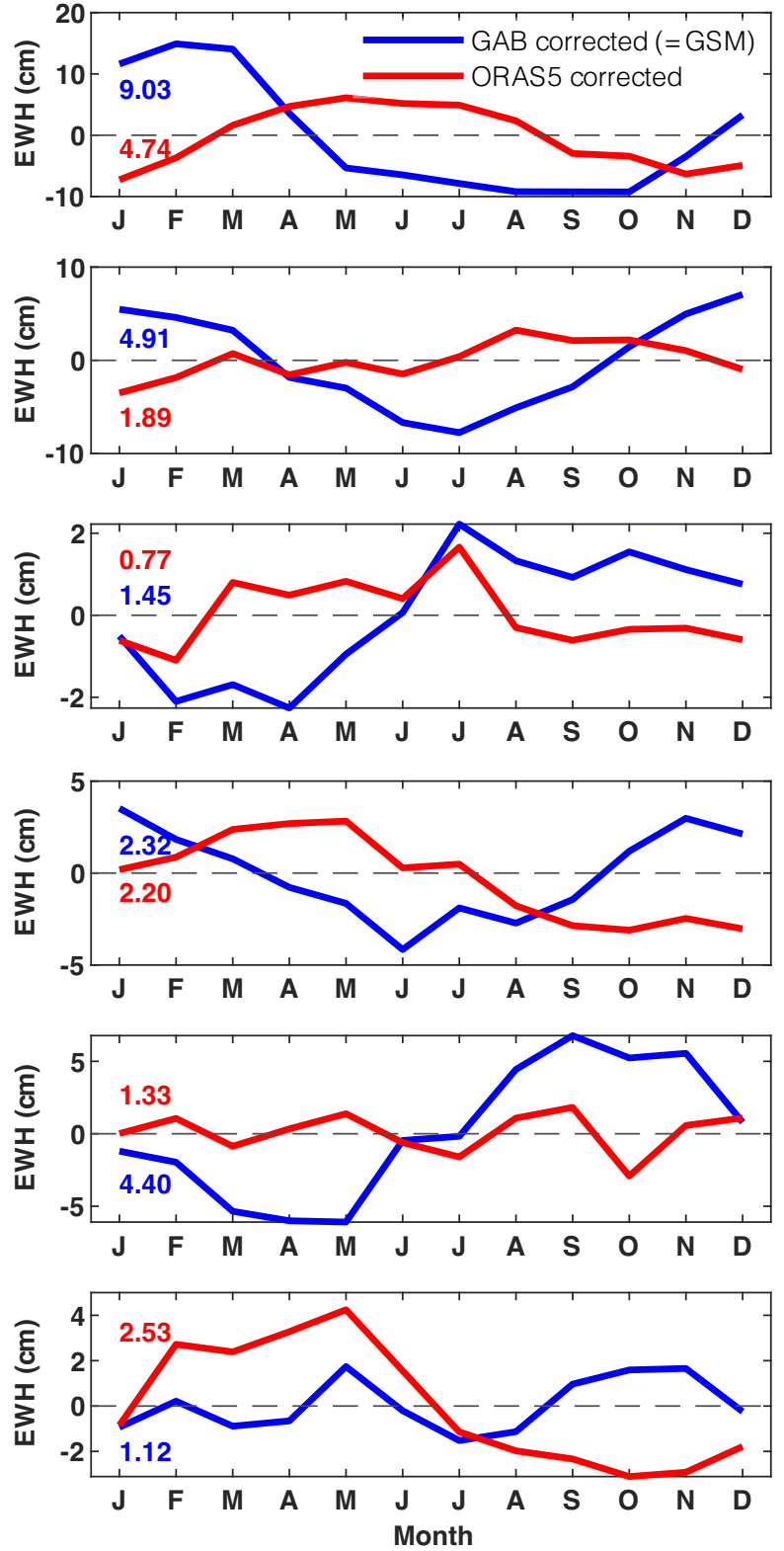

Figure 3. Seasonal EWH changes by various products at the six locations marked in Fig. 2. The total ocean mass is derived by the sum of the GAB and GSM products. The red/blue numbers in the right column represent the rms of the corrected series and lower values indicate better model performance.

roughly remove signals on land by setting grids on land to zero and the smaller residual land-to-ocean leakage is symbolized as $\delta L_{\text {land }}$. Second, the global gridded values are expanded back into SHCs (eq. 4), which is again converted to EWH, but with a filter. Ocean areas within 1.5 times of the smoothing radius to the shoreline in the later result are further discarded to completely remove $\delta L_{\text {land }}$. This two-step procedure is necessary because $L_{\text {land }}$ has an influence zone much further than $\delta L_{\text {land }}$.

Although $L_{\text {land }}$ has been removed, another problem arises - there is no data in the offshore oceans as we have discarded these observations. One simple way is to interpolate the available observations in the nearby oceanic areas to get these data. It is assumed that the nearshore grids can be represented by the nearby grids which are not discarded.
The revised method for estimating ocean mass and removing its leakage effect is shown in Fig. 6. The method has three inputs: the GSM and GAB products of GRACE and one ocean mass model (here, ORAS5). First, the land signals are roughly removed by setting unsmoothed land grids calculated from GSM to zero (Fig. 6a). The ocean grids are expanded back into SHCs and smoothed by a $500 \mathrm{~km}$ Gaussian filter when converted again into gridded observations (Fig. 6b).

Second, the ocean variations are reduced by the ocean mass products according to eq. (7) (Fig. 6e). As introduced above, there is still a small part of land-to-ocean leakage in the coastal oceans, so we discard grids within $750 \mathrm{~km}$ from the shoreline (i.e. 1.5 times the smoothing radius) (Fig. 6d) and use a 2-D linear interpolation to fill these gaps (Fig. 6f). Therefore, we obtain the residual ocean 
(a) ORAS5_corrected_ocean_mass / GSM

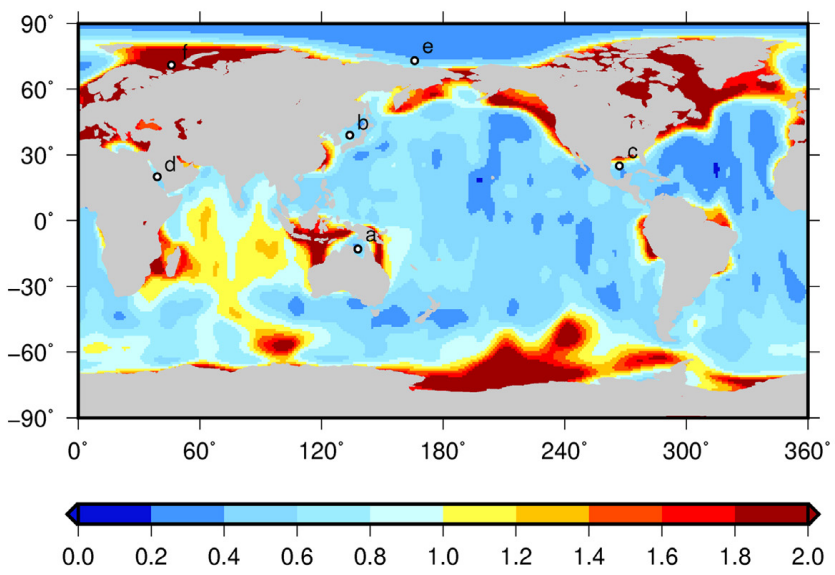

(b) RMS of residuals by joint correction

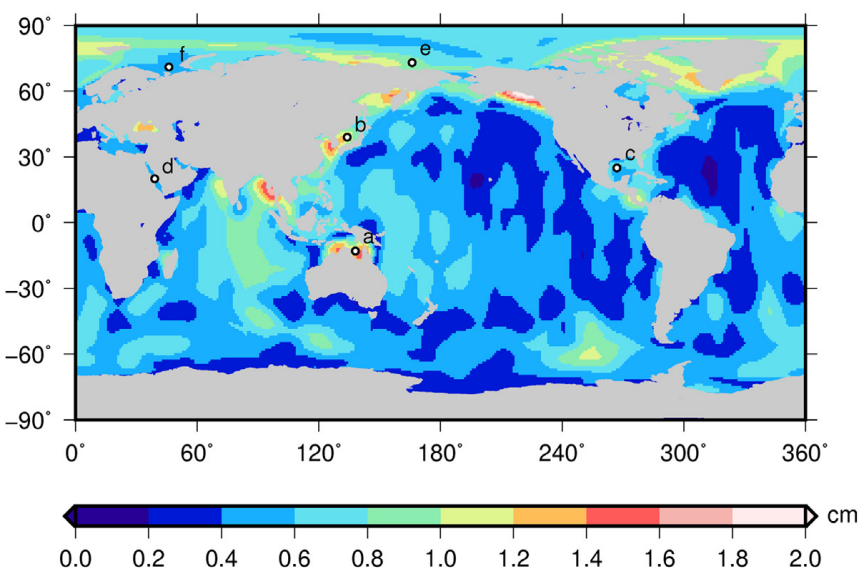

Figure 4. (a) Comparison of ORAS5- and GAB- corrected ocean mass anomalies. (b) RMS result of the joint inversion. In the joint correction, either the ORAS5 or the GAB model with a better performance is used. This can be compared to Fig. 2(b) to check the improvement (the lower the better). The ORAS5 model always outperforms the GAB product in open oceans, but in areas within $500 \mathrm{~km}$ from the coast, only 42 per cent of grids show a reduced rms value when the ORAS5 model is applied.

(a) ORAS5 corrected ocean mass anomalies

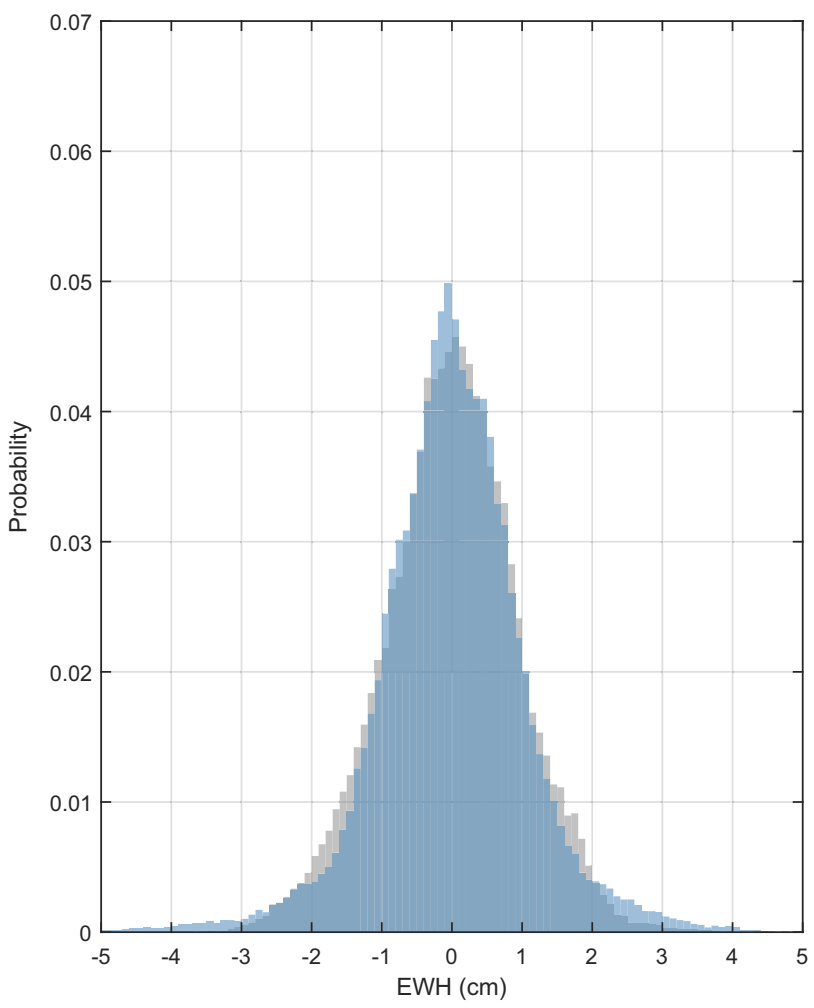

(b) Jointly corrected ocean mass anomalies

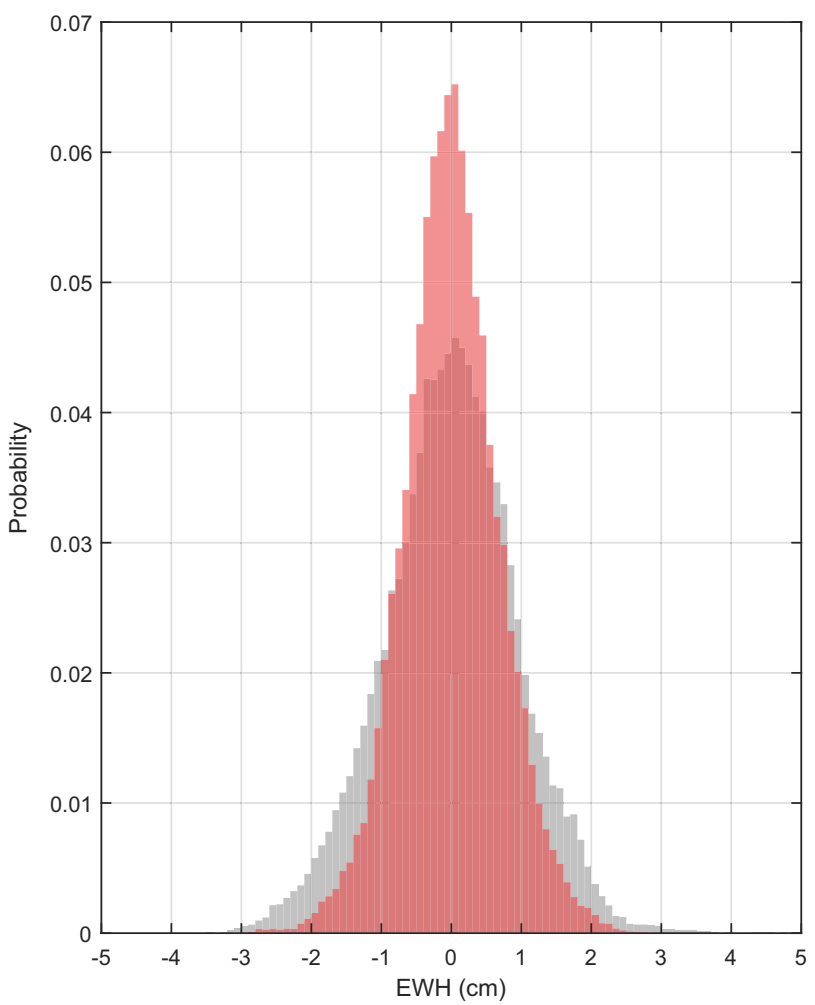

Figure 5. Histogram of ocean mass anomalies in coastal $(\leq 500 \mathrm{~km})$ ocean grids. The grey histogram behind each plot shows the result of the GSM product (i.e. GAB corrected).

signals (or the model imperfection, $e$ ). This residual signal of $e$ is then subtracted from the GSM (Fig. 6g), so all ocean mass has been removed (Fig. 6h). Finally, we recover the land signal by the traditional forward modelling method. No ocean layer is needed in this step since ocean-to-land leakage has already been removed.
The forward modelling method is specified in four steps:

(i) The smoothed EWH observation $f_{0}$ on land is taken as a hypothesized mass $m_{0}$ (in the unit of EWH) with a spatial resolution of $1^{\circ}$ by $1^{\circ}$. 


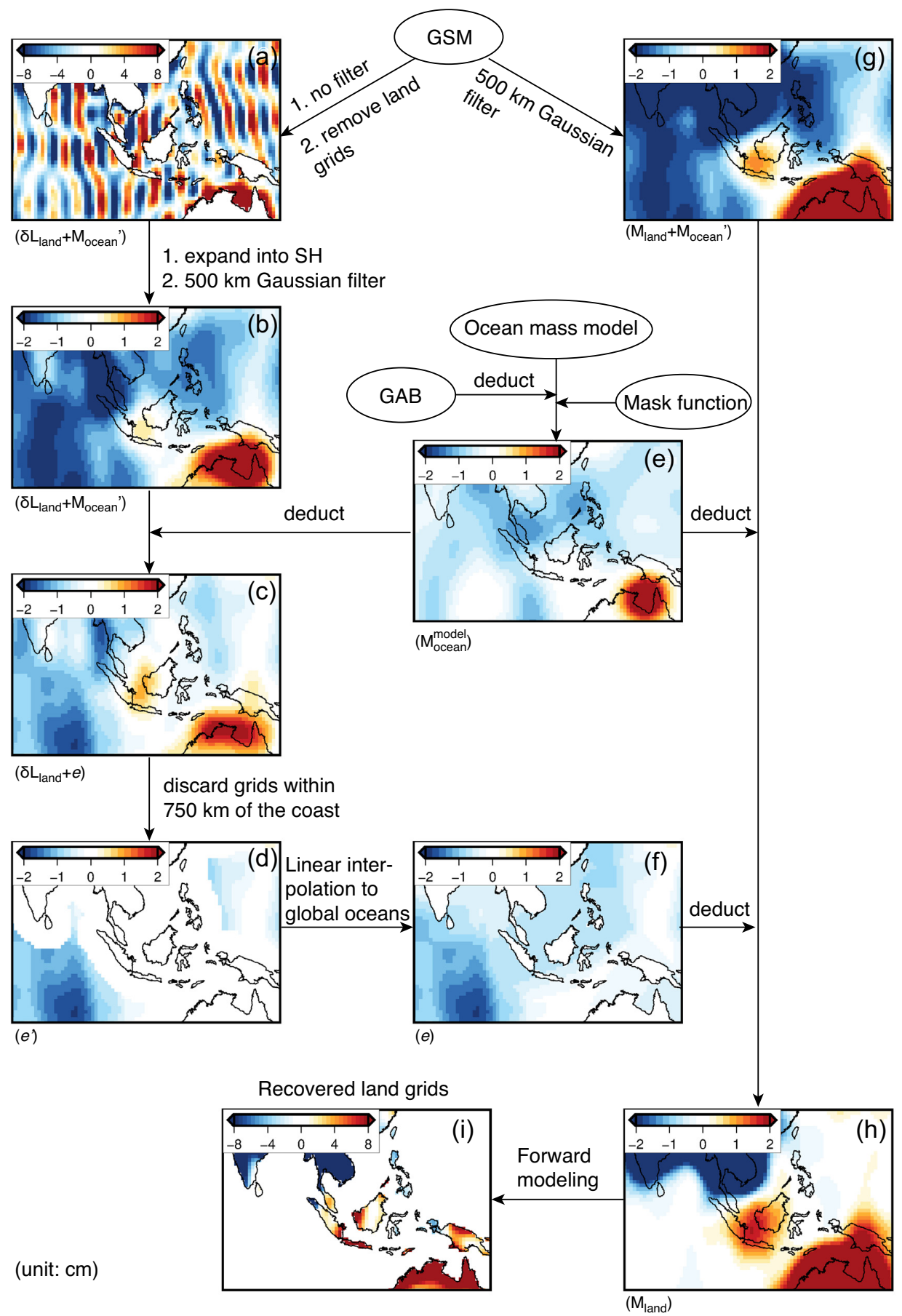

Figure 6. Flow chart of the non-uniform forward modelling method. The expression below each plot shows the composition of the signals. M represents mass, $\mathrm{L}$ represents leakage and $e$ represents model imperfection. The apostrophe sign indicates the value is changed/biased. Note that the method has global coverage, while the Southeastern Asia is shown as a regional demonstration.

(ii) The mass $m_{0}$ is then expanded into SHCs, and the same smoothing technique used above is applied. In this way, the recovered signal $f_{1}$ is obtained.

(iii) The difference between the GRACE observation and the recovered signal $\left(f_{0}-f_{1}\right)$ is added to the mass $m_{0}$.

(a) The steps (b) and (c) iterate after a fixed number of steps or until the observed signal is mostly recovered. To speed up the convergence, an amplifier of 1.5 is often used in step three, that is $m_{0}=m_{0}+1.5 \times\left(f_{0}-f_{1}\right)$. Please note that the low degrees are intact.

\section{RESULTS OF THE OCEAN-TO-LAND LEAKAGE EFFECT}

To find out the importance of the ocean-to-land leakage, we compare the results by three methods:

M1: the forward modelling method without ocean mass correction. 

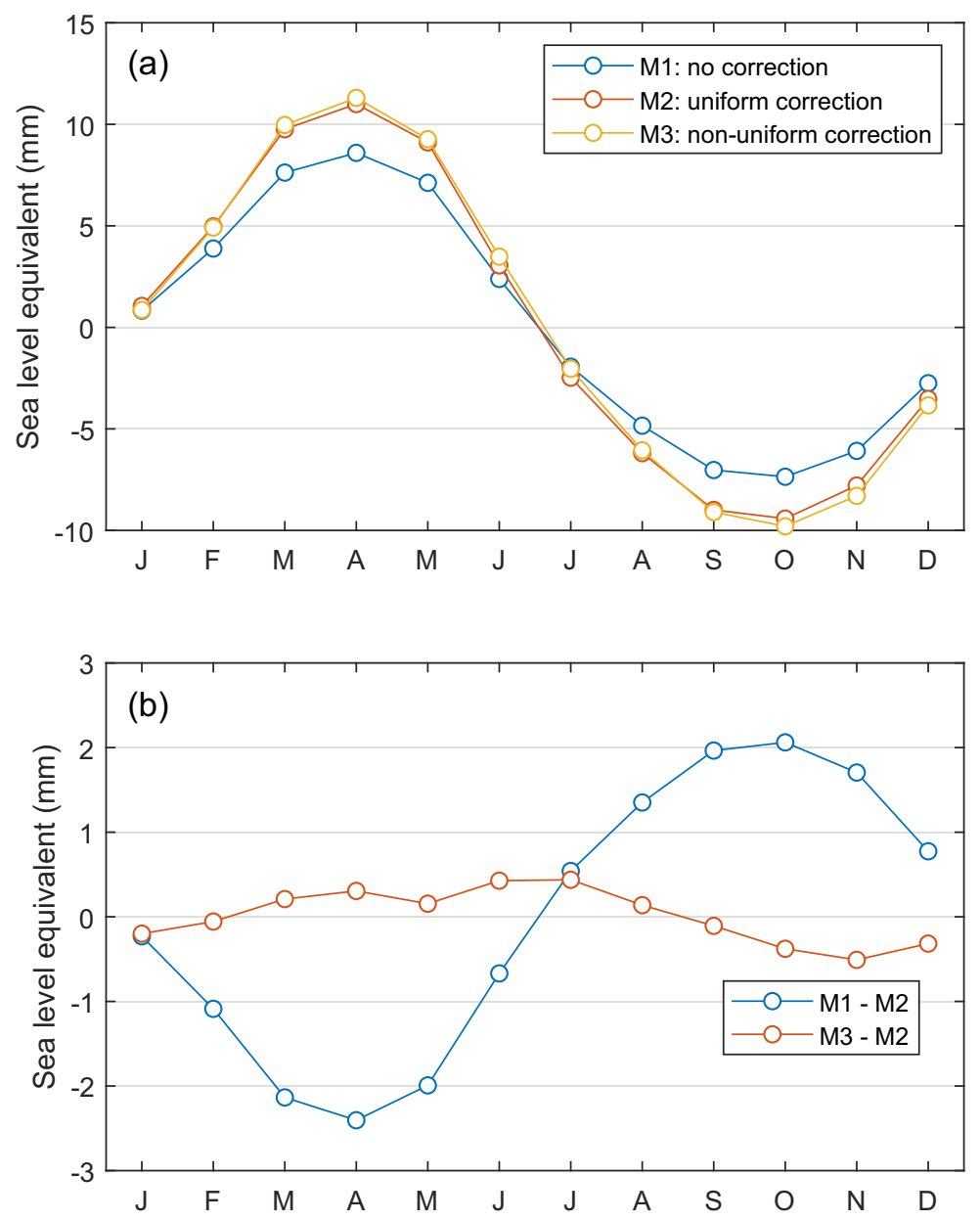

Figure 7. Global mass change in EWH by three ocean mass correction strategies. The results and their differences are given in (a) and (b), respectively. The M1 method underestimates the result by $\sim 20$ per cent, and the M2 and M3 methods produce similar results in seasonal variations.

M2: the uniform ocean layer is used, so it is the same as previously used (Chen et al. 2013; Yi et al. 2017).

M3: the non-uniform ocean layer is used, which is the method proposed in this study.

\subsection{Investigation at the seasonal temporal scale}

The globally average of seasonal variations in land water storage from the three methods is shown in Fig. 7. The land mass is converted into sea level equivalent at a ratio of $1 / 361.7 \mathrm{~mm} \mathrm{Gt}^{-1}$. The ocean-to-land leakage, up to $2.4 \mathrm{~mm}$, always accounts for $\sim 20$ per cent of the total mass anomaly, so failing to consider it will always cause an underestimation of the total mass anomaly by $\sim 20$ per cent compared with a uniform ocean layer correction. The non-uniform effect is not significant at the global scale, and the difference between uniform and non-uniform effects is always smaller than $0.5 \mathrm{~mm}$, which is close to the mean GRACE data error of $0.4 \mathrm{~mm}$ [propagated from the calibrated errors of SHCs (Yi et al. 2016)]. Therefore, it is acceptable to not consider the non-uniform distribution in ocean mass if only the global mean is targeted.

Despite the small discrepancies between uniform and nonuniform correction at the global scale, their regional differences are remarkable. In Fig. 8, we show the details in October when the largest difference among these methods occurs. In October, tremendous mass is lost from the land, so the ocean generally rises by an average of $\sim 0.9 \mathrm{~cm}$. This leads to a significant ocean-to-land leakage and without considering it, the coastal land mass will generally be positively biased (Fig. 8c). However, the pattern of the ocean mass distribution is far from homogeneous. A faster-than-average accumulation is recognizable in the Arctic Ocean, the South China Sea, the Caribbean Sea and others (Fig. 8b). If a global average is used in these regions, the ocean-to-land leakage will be insufficiently considered so the nearby land mass will still be positively biased. With the non-uniform correction, we can find that the land mass is significantly smaller in these regions compared with the uniform correction (Fig. 8d).

The statistical distribution of the difference in land grids is calculated separately in near-shore areas (within $500 \mathrm{~km}$ of coastline) and the others (Figs 8e and $\mathrm{f}$ ). These three methods put little effect on mass change estimates of hinterland grids and the differences are concentrated only in the coastal regions. In both cases of M1M2 and M3-M2, 40 per cent of grids differ by more than $1 \mathrm{~cm}$. Globally, the difference between M3 and M2 is close to a symmetric distribution, so the total sum is not large. The difference in coastal 
(a) October of GSM

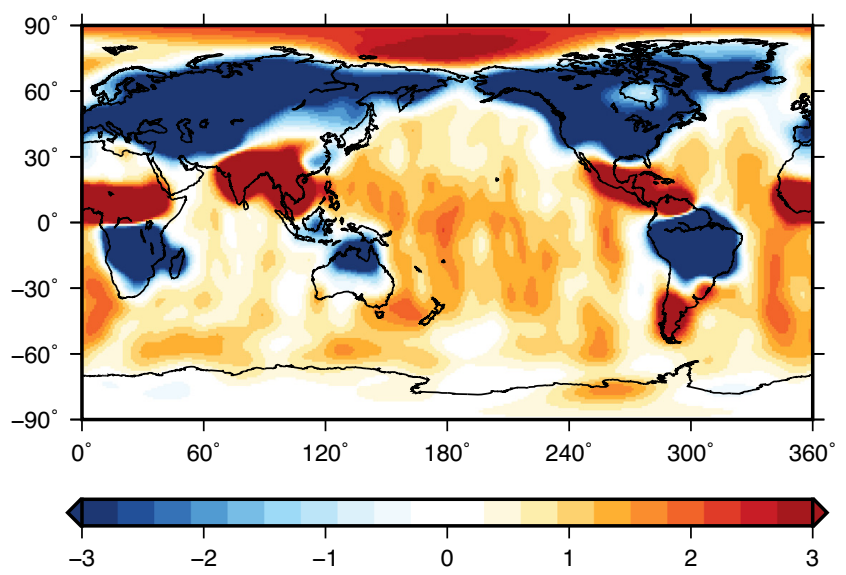

(c) $\mathrm{M} 1-\mathrm{M} 2$

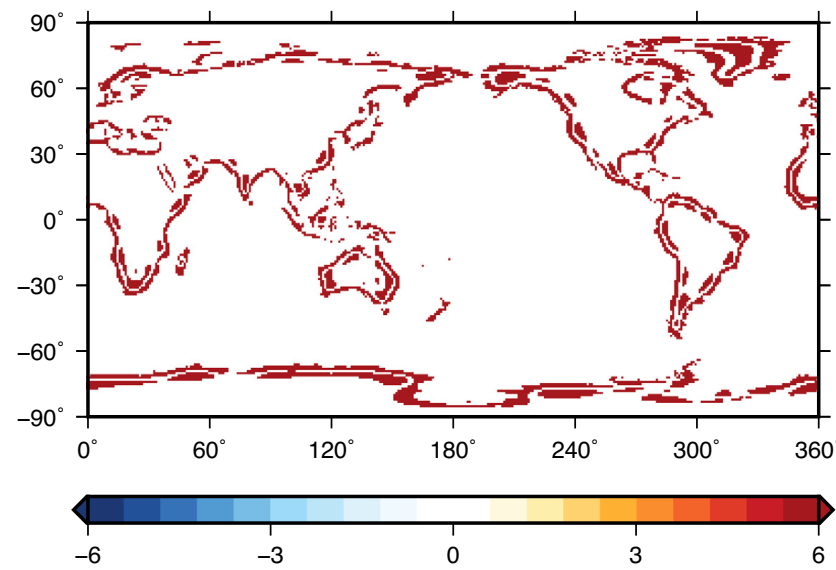

(e) Histogram of M1 - M2

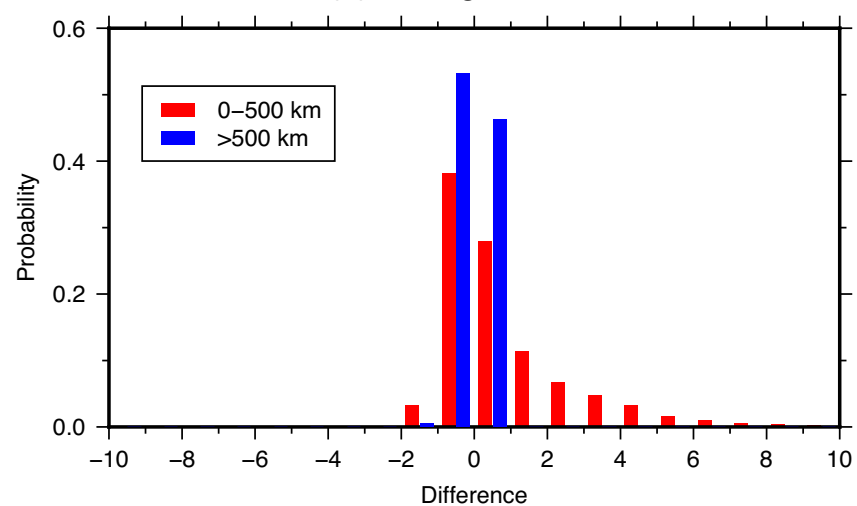

(b) Derived ocean mass in GSM

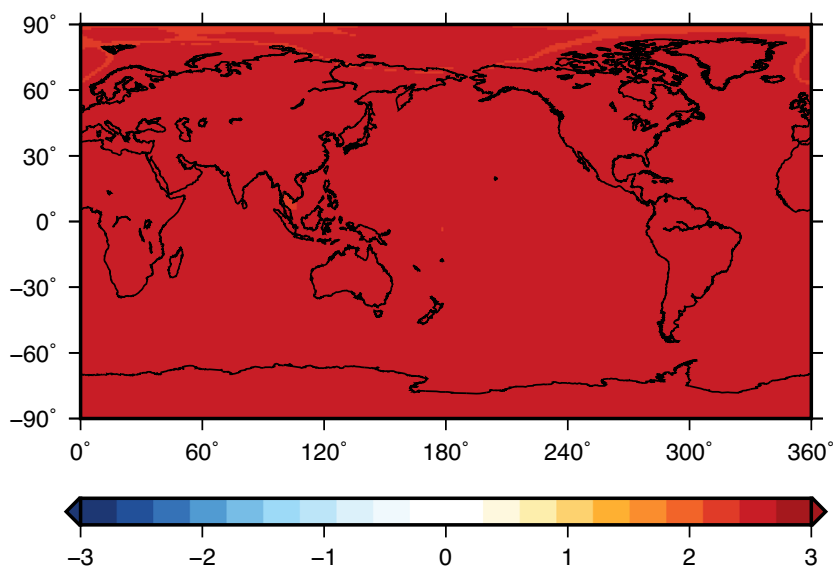

(d) $M 3-M 2$

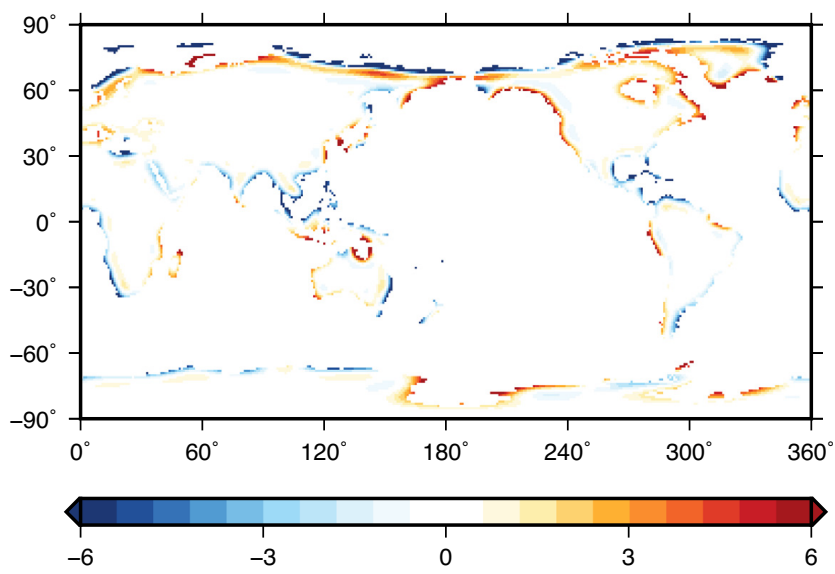

(f) Histogram of $\mathrm{M} 3-\mathrm{M} 2$

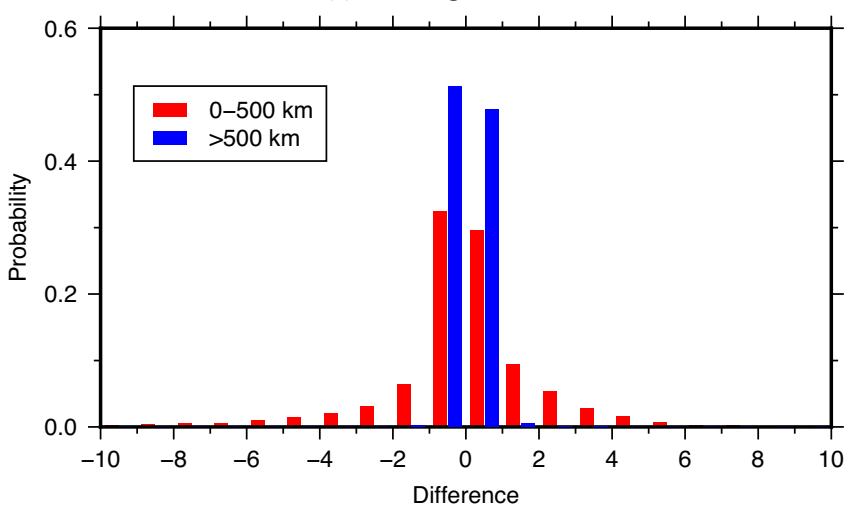

Figure 8. Demonstration of the influence of different ocean mass corrections in mass estimate in terms of EWH in October (when the total ocean mass reaches the peak). The derived ocean mass (b) is based on M3. The difference of mass estimate by M1 and M2 is given in (c) and (e) and that by M3 and M2 is given in (d) and (f). The probability of the difference is separated into two categories: land grids within $500 \mathrm{~km}$ of the shoreline and the others ( $>500 \mathrm{~km})$. The unit is $\mathrm{cm}$. It shows that the differences are mainly concentrated in coastal areas.

regions is generally smaller than $6 \mathrm{~cm}$, but can be several dozens of centimetres in extreme cases (mainly in isolated islands).

The RMS of difference over 12 months is given in Fig. 9. Comparison of results without correction and with uniform correction shows that the difference can be $1-3 \mathrm{~cm}$ in most coastal regions and larger in islands. The non-uniform correction brings a comparable difference near these coastal regions. The difference grows to $10 \mathrm{~cm}$ or even larger in some coastal land grids, for example those surrounding the Arctic Ocean, the Sea of Japan and the Gulf of Carpentaria, where GSM shows strong variations (Fig. 2). This distribution puts a caution that the non-uniform ocean-to-land leakage will have an effect of at least $1 \mathrm{~cm}$ in all coastal regions and could be even remarkable in the regions mentioned above, so it is unacceptable to ignore this effect in any study of coastal mass variation. 
(a) RMS(M1 - M2)

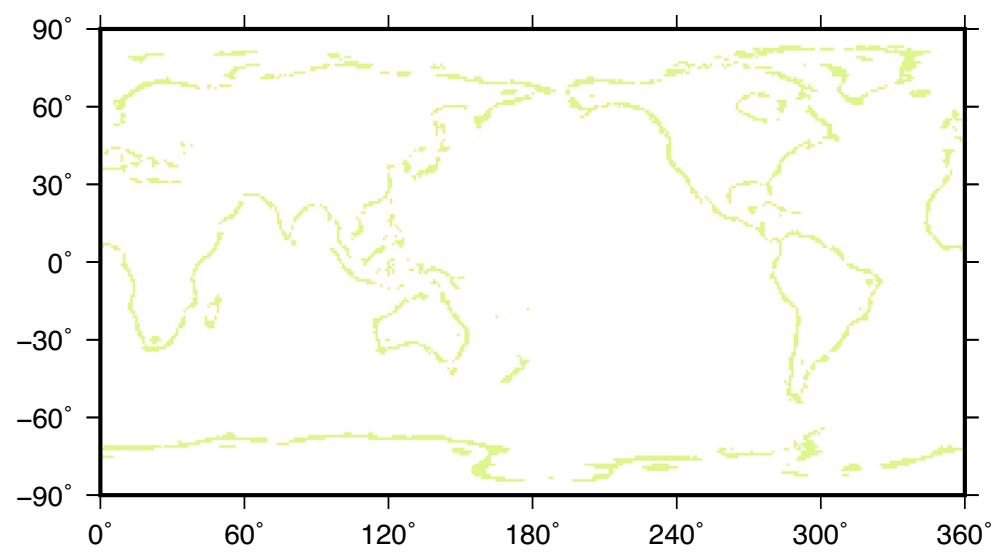

(b) RMS(M3 - M2)

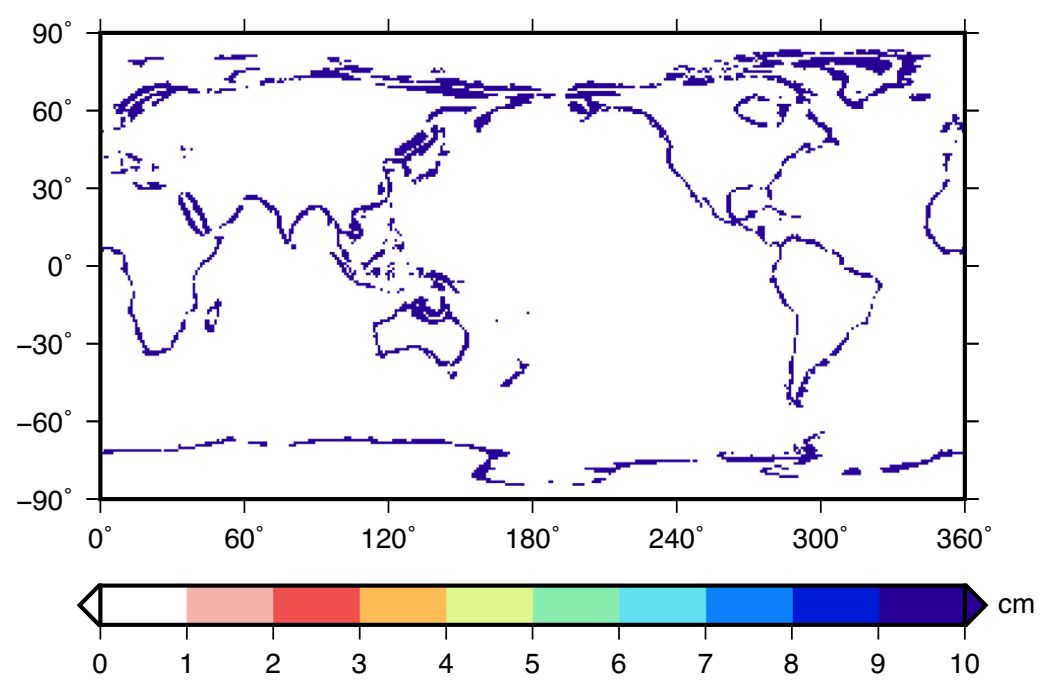

Figure 9. Rms of mass difference in terms of EWH by (a) M1 and M2 and (b) M3 and M2. The difference concentrates in coastal areas, and the consideration of non-uniformity in ocean mass distribution will greatly influence mass estimates in land grids around the Gulf of Carpentaria, the Sea of Japan and the Arctic Ocean.

\subsection{Investigation on the long-term trend}

\subsubsection{Global mass trend between 2003 and 2016}

The decadal scale (2003-2016) of ocean-to-land leakage pattern is quite different from the seasonal scale one. Due to the higher signal-to-noise ratio in the secular trend than in the seasonal variation, we adopt a weaker filter here (a $400 \mathrm{~km}$ Gaussian filter).
The global map (Fig. 10) shows that mass in global oceans is increasing, while the Arctica Ocean and the Northern Pacific Ocean show a faster-than-average rate. One longitudinal profile (profile-A in Fig. 10) and one latitudinal profile (profile-B) are given to better reveal the non-uniform ocean mass distribution and its leakage effect. Profile-A crosses several well-studied regions: the Caspian Sea (Chen et al. 2017) the Tibet Plateau (Matsuo \& Heki 2010; Yi \& Sun 2014), the North China Plain (Feng et al. 2013), the 2011 Tohoku Earthquake (Wang et al. 2012) and the Central Valley in California (Famiglietti et al. 2011; Scanlon et al. 2012). The latter two are located in coastal regions and their signals are clearly mixed up with the ocean signals, that is due to the ocean water mass increase, the gravity increase observed near the rupture zone of the 2011 Tohoku Earthquake is enhanced, while the gravity decrease caused by water consumption in the Central Valley is reduced. As shown in the profile- $\mathrm{B}$, such a leakage is particularly severe in Alaska, where the mass of the surrounding oceans is increasing much faster than the global average. Both profiles show that the increase in ocean mass is inhomogeneous. For example, the rate of mass increase in the Atlantic Ocean diminishes eastward across the profile-A, while global ocean mass shows a 


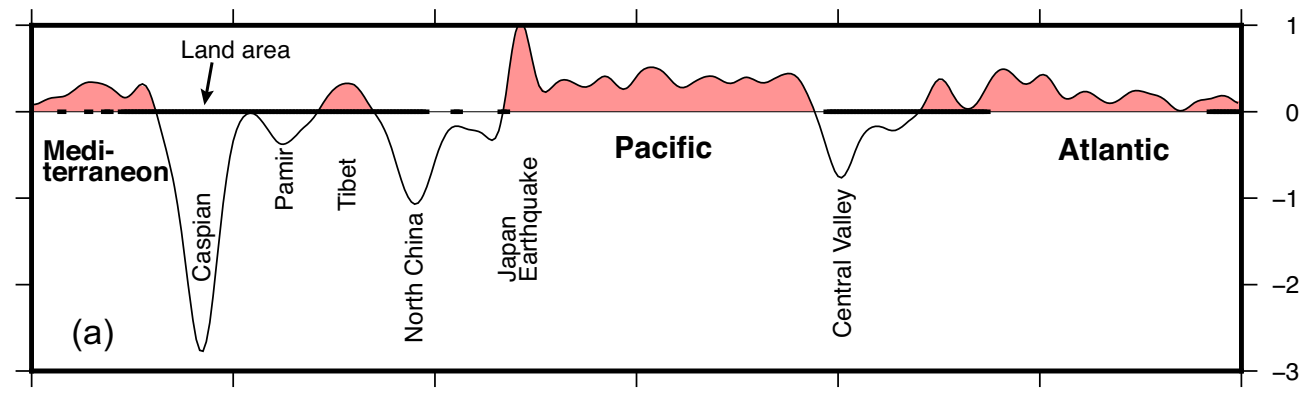

(unit: $\mathrm{cm} / \mathrm{yr}$ )

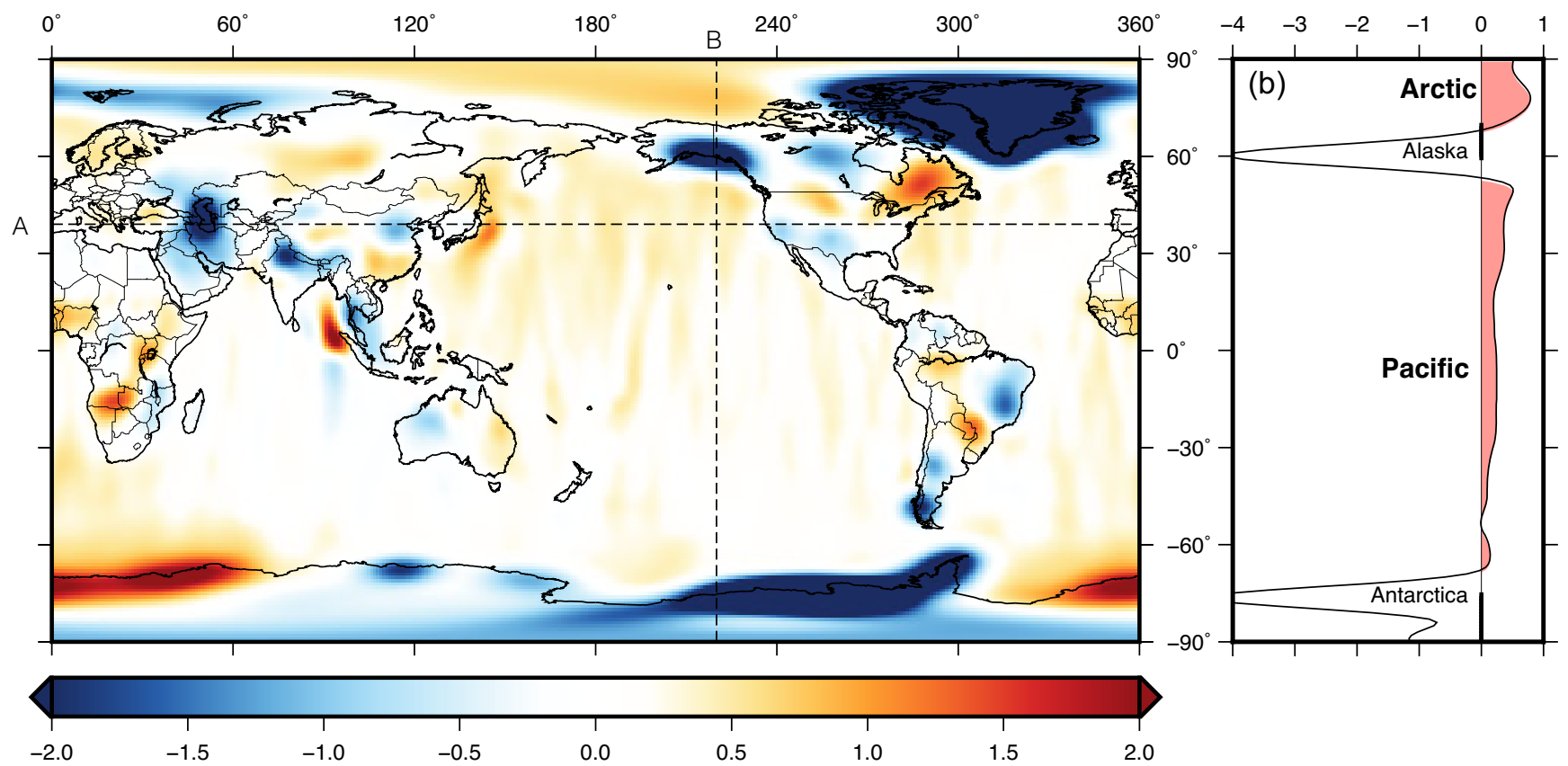

Figure 10. Trend of the GRACE GSM product in EWH between 2003 and 2016 under $400 \mathrm{~km}$ Gaussian filter. Two profiles of A and B are given. Note the uneven ocean mass increase and its mixture with land signals. The glacial isostatic adjustment effect is removed by the model of (A et al. 2013).

southward decreasing accumulation rate across the profile-B. Such a distribution is more heterogeneous than the prediction of sea level fingerprints (Mitrovica et al. 2009; Hsu \& Velicogna 2017), implying that the ocean dynamic effect is not negligible in the timescale of $14 \mathrm{yr}$.

\subsubsection{A case study in the Central Valley in the U.S.}

The influence of the ocean-to-land leakage in long-term trends varies from place to place. Here we take the Central Valley as an example. The Central Valley plays an important role in food production in the United States and its irrigation heavily depends on groundwater, especially during droughts (Famiglietti et al. 2011; Scanlon et al. 2012). As a result, the groundwater has been decreasing for the last century (Faunt 2009). The decreasing mass trend is well captured by GRACE during the satellite mission. The trend of land mass change by M3 is shown in Fig. 11(a). The mass loss spreads along the Central Valley and gradually decreases with increasing distance from the coast. Its close distance to the coast causes a mixture of ocean and land signals in this region. To demonstrate the ocean-to-land leakage, we expand the estimated ocean mass into
SHC and apply a $500 \mathrm{~km}$ Gaussian filter (Fig. 11b). The leakage is up to $0.2 \mathrm{~cm}$ and decreases gradually with distance from the shoreline. The results of the three methods are compared in a longitudinal profile shown in Fig. 11(c). The total mass change in the Central Valley between $2005-2016$ by M1, M2, M3 is $-10.9 \mathrm{Gt}$, $-12.5 \mathrm{Gt},-13.3 \mathrm{Gt}$, respectively. Therefore, ocean-to-land leakage will bring a positive bias of $2.4 \mathrm{Gt}$, and a uniform ocean layer only corrects 65 per cent of this bias, because the mass of the ocean area adjacent to the Central Valley is growing faster than the global average $(0.34 \mathrm{~cm}$ compared with $0.21 \mathrm{~cm})$. The trough value of the groundwater mass change along the profile is reduced and even shifted eastward if the ocean-to-land leakage is not properly corrected.

\section{DISCUSSION ON THE RELIABILITY AND UNCERTAINTY OF THE METHOD}

The method of estimating ocean mass distribution relies heavily on an ocean mass model. The adoption of the ocean model is crucial, because it can greatly reduce the fluctuation of ocean signals and guarantee reliable interpolation. This is extremely important for certain nearshore variations that cannot be recovered by the interpolation. For example, the strong signal in the Gulf of Carpentaria can be reduced by the model in advance. However, we expect the model 

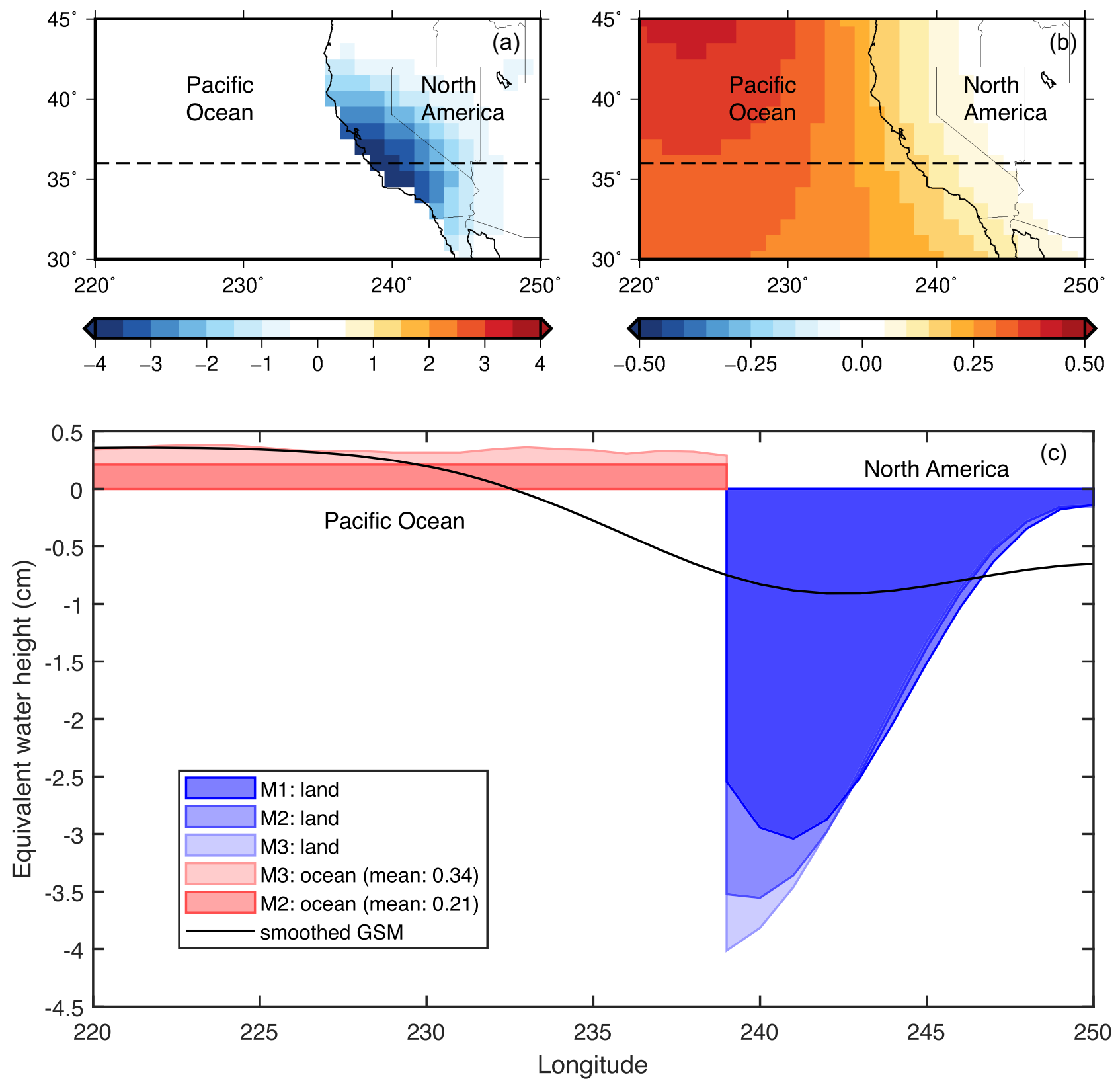

Figure 11. Terrestrial (a) and smoothed ocean (b) mass trends in terms of EWH from the GSM estimated by M3. (c) Comparison of mass trends by three methods along the profile marked by the dashed line in (a). The unit is $\mathrm{cm}$.

could remove as many of these signals as possible, but the residual signals, originating from defects in the ocean model, may still be large. This bias only influences short-wavelength oceanic variations but not long-wavelength ones, because afterward we deduct the interpolated residuals from GSM. This step guarantees that the ocean mass model does not bring in a different net mass change from that of GRACE and that GSM is self-consistent in the sum of global mass.

In our forward modelling method, we used a $500 \mathrm{~km}$ Gaussian filter to suppress noise. Although different filters may have a large influence on regional mass estimates, their integrated impact on the global oceans is well below other uncertainties. As shown in Fig. 12, we tested two Gaussian filters and two DDK filters (Kusche et al.
2009), and the difference among the results is less than $0.1 \mathrm{~mm}$, which is negligible compared with its estimates at the order of $\pm 10 \mathrm{~mm}$ (Fig. 7). Note that the DDK1 filter is usually excessively strong and it generates the largest difference in our results, but even so, its influence is still acceptable.

The ocean mass model relies on steric observations which are quite sparse before 2005, so we only use the product from 2005 onwards. From Fig. 2(e), we can find that the model does not perform well in higher latitudes and in the equatorial areas. Besides, by comparing GRACE and ORAS5, we find the trend of ORAS5 is not as reliable as its seasonal variation, so a global trend evaluation is not given here. These flaws in the ocean mass model could 


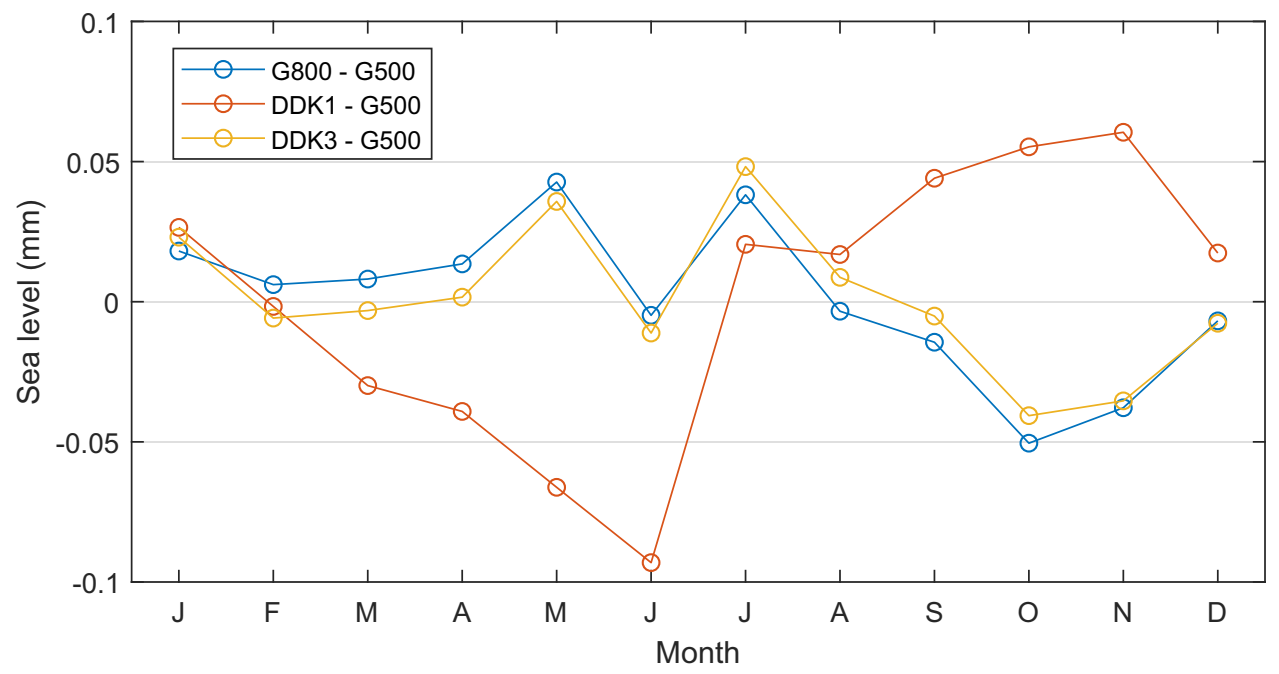

Figure 12. The influence of different filters on seasonal results. Two Gaussian filters with a radius of $500 \mathrm{~km}$ (G500) and $800 \mathrm{~km}$ (G800) and two DDK filters (DDK1 and DDK3) are used here and the result by G500 is taken as the benchmark. It shows that the global mean result is insensitive to the choice of filters considering its varied range of $\pm 10 \mathrm{~mm}$.

impede an accurate estimation and correction of the ocean signal leakage.

The necessary implementation of the ocean mass model is due to the poor performance of the GAB/GAD product in the simulation of non-tidal ocean mass variations. If the $\mathrm{GAB} / \mathrm{GAD}$ product can fully simulate the short-wavelength variations, then we can just interpolate to recover long-wavelength residuals without introducing an ocean mass model.

On the other hand, if the ocean mass model is improved in the future and has a precision below the GRACE data error, Fig. 6(f) will only contain errors. We then only need to deduct Fig. 6(e) from Fig. 6(g) to get Fig. 6(h) and the other steps can simply be omitted. However, the strong residual signals in Fig. 6(f) seem to be far more than noise. In conclusion, this method can be much simplified if either the GAB/GAD product or the ocean mass model is improved in the future to make them sufficiently accurate.

\section{CONCLUSION}

In this study, we propose a new global forward modelling method with non-uniform ocean mass correction to estimate the heterogeneous ocean mass distribution in GRACE observations. The main principle of the method is to incorporate the ocean mass model ORAS5 to remove the major ocean mass signals, so that the residual ones can be recovered by spatial interpolation with high accuracy. Due to the imperfection in the model, we adopt joint correction to make full use of both the ORAS5 and GAB products. We use three methods to deal with the ocean mass correction (no correction, uniform correction and non-uniform correction), compare the results, and find the biases are different at different temporal and spatial scales. In the seasonal study, failing to account for the ocean mass correction will always bring an underestimation of $\sim 20$ per cent and a uniform correction is sufficient at the global scale, but it is necessary to consider the spatial variation of the ocean mass distribution in local coastal regions because the deviation can be up to tens of centimetres. In the long-term trend, the influence is different in different regions depending on the signal characteristics. We demonstrate by the case of groundwater depletion in the Central Valley that the secular trend may be biased by several gigatons and the uniform ocean leakage correction is only able to correct $2 / 3$ of it. Based on these results, we conclude that the ocean-to-land leakage in GRACE is non-uniform and non-negligible. This method relies heavily on ocean mass models and the steps could be greatly simplified if either the $\mathrm{GAB} / \mathrm{GAD}$ product or the ocean mass model has sufficiently high accuracy in the future.

\section{ACKNOWLEDGEMENTS}

This research is supported by JSPS KAKENHI Grant JP16F16328 and the Alexander von Humboldt Foundation. The authors are grateful for these publicly available GRACE products provided by ICGEM (http://icgem.gfz-potsdam.de/home) and ORAS5 data provided by the University of Hamburg (http://icdc.cen.uni-hamburg .de/projekte/easy-init/easy-init-ocean.html).

\section{REFERENCES}

Baur, O., Kuhn, M. \& Featherstone, W.E., 2009. GRACE-derived ice-mass variations over Greenland by accounting for leakage effects, J. geophys. Res., 114(B6), B06407, doi:10.1029/2008JB006239.

Bettadpur, S., 2012, Level-2 Gravity Field product User Handbook, Center for Space Research, The University of Texas at Austin, Austin, TX.

Chambers, D.P., Cazenave, A., Champollion, N., Dieng, H., Llovel, W., Forsberg, R., Von Schuckmann, K. \& Wada, Y., 2017. Evaluation of the global mean sea level budget between 1993 and 2014, Cazenave, A., Champollion, N., Paul, F. \& Benveniste , J.. in Integrative Study of the Mean Sea Level and Its Components, 58, Springer International Publishing, (Cham), 315-333.

Chen, J.L., Wilson, C.R. \& Tapley, B.D., 2013. Contribution of ice sheet and mountain glacier melt to recent sea level rise, Nat. Geosci., 6(7), 549-552.

Chen, J.L., Wilson, C.R., Tapley, B.D., Save, H. \& Cretaux, J.-F., 2017. Long-term and seasonal Caspian Sea level change from satellite gravity and altimeter measurements, J. geophys. Res., 122(3), 2274-2290.

Cheng, M., Ries, J.C. \& Tapley, B.D., 2011. Variations of the Earth's figure axis from satellite laser ranging and GRACE, J. geophys. Res., 116(B1), doi:10.1029/2010jb000850.

Church, J.A. et al., 2013. Sea Level Change: PM, Cambridge Univ. Press.

Dieng, H.B., Cazenave, A., Meyssignac, B. \& Ablain, M., 2017. New estimate of the current rate of sea level rise from a sea level budget approach, Geophys. Res. Lett., 44(8), 3744-3751. 
Dobslaw, H., Bergmann-Wolf, I., Dill, R., Poropat, L. \& Flechtner, F., 2017. AOD1B product description document for product release 06 (Rev. 6.1, October 19, 2017).

Famiglietti, J. et al., 2011. Satellites measure recent rates of groundwater depletion in California's Central Valley, Geophys. Res. Lett., 38(3), doi:10.1029/2010GL046442.

Faunt, C.C., ed., 2009. Groundwater Availability of the Central Valley Aquifer, U.S. Geological Survey Professional Paper 1766, 225pp.

Feng, W., Zhong, M., Lemoine, J.-M., Biancale, R., Hsu, H.-T. \& Xia, J., 2013. Evaluation of groundwater depletion in North China using the Gravity Recovery and Climate Experiment (GRACE) data and groundbased measurements, Water Resour. Res., 49(4), 2110-2118.

Fofonoff, N.P. \& Millard, R., Jr., 1983. Algorithms for the computation of fundamental properties of seawater, UNESCO, Paris, France, 53 pp. (UNESCO Technical Papers in Marine Sciences; 44), http://hdl.handle.net/11329/109.

Gardner, A.S. et al., 2013. A reconciled estimate of glacier contributions to sea level rise: 2003 to 2009, Science, 340(6134), 852-857.

A, G., Wahr, J. \& Zhong, S., 2013. Computations of the viscoelastic response of a 3-D compressible Earth to surface loading: an application to Glacial Isostatic Adjustment in Antarctica and Canada, Geophys. J. Int., 192(2), 557-572.

Guo, J.Y., Duan, X.J. \& Shum, C.K., 2010. Non-isotropic Gaussian smoothing and leakage reduction for determining mass changes over land and ocean using GRACE data, Geophys. J. Int., 181(1), 290-302.

Hsu, C.-W. \& Velicogna, I., 2017. Detection of sea level fingerprints derived from GRACE gravity data, Geophys. Res. Lett., 44(17), 8953-8961.

Huang, Z., Jiao, J.J., Luo, X., Pan, Y. \& Zhang, C., 2019. Sensitivity analysis of leakage correction of GRACE data in Southwest China using a-priori model simulations: inter-comparison of spherical harmonics, mass concentration and in situ observations, Sensors, 19(14), 3149, doi: $10.3390 / \mathrm{s} 19143149$.

Jeon, T., Seo, K.-W., Youm, K., Chen, J. \& Wilson, C.R., 2018. Global sea level change signatures observed by GRACE satellite gravimetry, Scient. Rep., 8(1), 13519, doi:10.1038/s41598-018-31972-8.

King, M.A., Bingham, R.J., Moore, P., Whitehouse, P.L., Bentley, M.J. \& Milne, G.A., 2012. Lower satellite-gravimetry estimates of Antarctic sealevel contribution, Nature, 491(7425), 586.

Kusche, J., Schmidt, R., Petrovic, S. \& Rietbroek, R., 2009. Decorrelated GRACE time-variable gravity solutions by GFZ, and their validation using a hydrological model, J. Geod., 83(10), 903-913.

Luthcke, S.B., Sabaka, T., Loomis, B., Arendt, A., JJ, M. \& Camp, J., 2013. Antarctica, Greenland and Gulf of Alaska land-ice evolution from an iterated GRACE global mascon solution, J. Glaciol., 59(216), 613-631.

Matsuo, K. \& Heki, K., 2010. Time-variable ice loss in Asian high mountains from satellite gravimetry, Earth planet. Sci. Lett., 290(1-2), 30-36.
Mitrovica, J.X., Gomez, N. \& Clark, P.U., 2009. The sea-level fingerprint of West Antarctic collapse, Science, 323(5915), 753-753.

$\mathrm{Mu}, \mathrm{D} ., \mathrm{Xu}, \mathrm{T}$. \& Xu, G., 2019. Detecting coastal ocean mass variations with GRACE mascons, Geophys. J. Int., 217(3), 2071-2080.

Scanlon, B.R., Longuevergne, L. \& Long, D., 2012. Ground referencing GRACE satellite estimates of groundwater storage changes in the California Central Valley, USA, Water Resour. Res., 48(4), doi:10.1029/2011wr011312.

Swenson, S., Chambers, D. \& Wahr, J., 2008. Estimating geocenter variations from a combination of GRACE and ocean model output, J. geophys. Res., 113(B8), doi:10.1029/2007JB005338.

Sørensen, L.S., Jarosch, A.H., Aðalgeirsdóttir, G., Barletta, V.R., Forsberg, R., Pálsson, F., Björnsson, H. \& Jóhannesson, T., 2017. The effect of signal leakage and glacial isostatic rebound on GRACE-derived ice mass changes in Iceland, Geophys. J. Int., 209, 226-233.

Uebbing, B., Kusche, J., Rietbroek, R. \& Landerer, F.W., 2019. Processing choices affect ocean mass estimates from GRACE, J. geophys. Res., 124(2), 1029-1044.

Velicogna, I. \& Wahr, J., 2006. Acceleration of Greenland ice mass loss in spring 2004, Nature, 443(7109), 329-331.

Watkins, M.M., Wiese, D.N., Yuan, D.-N., Boening, C. \& Landerer, F.W., 2015. Improved methods for observing Earth's time variable mass distribution with GRACE using spherical cap mascons: improved Gravity Observations from GRACE, J. geophys. Res., 120(4), 2648-2671.

Wahr, J., Molenaar, M. \& Bryan, F., 1998. Time variability of the Earth's gravity field: hydrological and oceanic effects and their possible detection using GRACE, J. geophys. Res., 103(B12), 30205-30229.

Wang, L., Shum, C.K., Simons, F.J., Tapley, B. \& Dai, C., 2012. Coseismic and postseismic deformation of the 2011 Tohoku-Oki earthquake constrained by GRACE gravimetry, Geophys. Res. Lett., 39(7), doi:10.1029/2012g1051104.

Wiese, D.N., Landerer, F.W. \& Watkins, M.M., 2016. Quantifying and reducing leakage errors in the JPL RL05M GRACE mascon solution, Water Resour. Res., 52(9), 7490-7502.

Yi, S., Heki, K. \& Qian, A., 2017. Acceleration in the global mean sea level rise: 2005-2015, Geophys. Res. Lett., 44(23), 11 905-11913.

Yi, S. \& Sun, W., 2014. Evaluation of glacier changes in high-mountain Asia based on 10 year GRACE RL05 models, J. geophys. Res., 119(3), 2504-2517.

Yi, S., Wang, Q. \& Sun, W., 2016. Basin mass dynamic changes in China from GRACE based on a multibasin inversion method, J. geophys. Res., 121, 3782-3803.

Zuo, H., Balmaseda, M.A., Tietsche, S., Mogensen, K. \& Mayer, M., 2019. The ECMWF operational ensemble reanalysis-analysis system for ocean and sea-ice: a description of the system and assessment, Ocean Sci. Discuss., 2019, 1-44. 